Миличевич Н. М.

Миленович М. Б.

Маркович Д.

\author{
ВОЙНА И ПСИХОТРАВМА: РАЗМЫШЛЕНИЯ \\ О ПСИХИАТРИЧЕСКИХ ПОТЕРЯХ В ВОЙНАХ ХХ СТОЛЕТИЯ
}

Миличевич Небойша М., доктор психологических наук, доцент. Философский факультет Университета в Нише ул. Кирилла и Мефодия д. 2, г. Ниш, 18000, Республика Сербия. E-mail: nesa2206@gmail.com

Миленович Миодраг Б., доктор психологических наук, доцент. Философский факультет Университета в Нише ул. Кирилла и Мефодия д. 2, г. Ниш, 18000, Республика Сербия. E-mail: mbmilenovic @ gmail.com

Маркович Деян, доктор филологических наук, профессор. Философский факультет Университета в Нише ул. Кирилла и Мефодия д. 2, г. Ниш, 18000, Республика Сербия. E-mail: dejan.markovic@ filfak.ni.ac.rs

\begin{abstract}
Аннотация
В работе рассмотрены психические расстройства в истории военных конфликтов в различных регионах и способы их лечения. Психические расстройства в ходе военных действий довольно часто появляются не только у военных лиц, но и у гражданского населения. Поэтому отдельное внимание необходимо уделять профилактическим мерам и укреплению устойчивости к страху, тревожности и панике. В боевых подразделениях следует применять опыт прошлых войн, а также принципы поэтапного лечения психотравмированных лиц. Кроме рассмотрения феномена психиатрических потерь в последних войнах, на рассмотрение выносится опыт авторов и военных психологов по работе с солдатами и офицерами, участниками военных действий на просторах бывшей Югославии. Большинство из них имели симптомы посттравматического стрессового расстройства (ПТСР), которые становились все более интенсивными в мирное время. В статье рассказано о случаях солдат и офицеров, которые были направлены на специализированные психиатрические осмотры. Все приведенные данные говорят о необходимости проведения профилактических мероприятий, укреплении боевого духа и стрессоустойчивости, устранения тревожности и паники в чрезвычайных ситуациях.

Ключевые слова: посттравматический стресс; военный дух; страх.
\end{abstract}

Nebojsa M. Milicevic,

Miodrag B. Milenovic

Dejan Markovic

\section{WAR AND MENTAL TRAUMA: REFLECTIONS ON PSYCHIATRIC LOSSES IN WARS OF THE TWENTIETH CENTURY}

Milicevic Nebojsa M., Doctor of Psychological Sciences, Associate Professor. Faculty of Philosophy, State University of Nis 2 Cirila i Metodija, Nis, 18000, Serbia. E-mail: nesa2206@gmail.com

Milenovic Miodrag B., Doctor of Psychological Sciences, Associate Professor. Faculty of Philosophy, State University of Nis 2 Cirila i Metodija, Nis, 18000, Serbia. E-mail: mbmilenovic@ gmail.com

Marković Dejan, Doctor of Philology, Professor. Faculty of Philosophy, State University of Nis 2 Cirila i Metodija, Nis, 18000, Serbia. E-mail: dejan.markovic@ filfak.ni.ac.rs

\begin{abstract}
The paper reports on psychological disorders throughout the history of wars in different regions and various ways of their treatment. War related psychological disorders are common not only in war veterans and their superiors, but also in civilians. This is why preventive activities, such as strengthening the resistance to fear, anxiety and panic, are extremely important. The experience gained in previous wars should be relied upon when working with combat troops and the principles of treatment of psychologically traumatized should be applied in stages. In addition to discussing psychiatric losses in recent wars, we shall present our experiences as military psychologists with troops and commanders during recent wars on the territories of former Yugoslavia. The majority of cases reflected the symptoms of post-traumatic stress disorder (PTSD), while disorders occur and/or intensify after the war, in which trauma was suffered. The paper discusses the cases of several soldiers and commanders who were referred to specialists for psychiatric examination. The findings emphasize the importance of preventive activities to increase combat morale and of the necessity to strengthen resistance to fear and panic in war situations.
\end{abstract}

Keywords: post-traumatic stress disorder; combat morale; fear; prevention. 
Во время военных операций часто возникают психические расстройства и нарушения. Эти расстройства психики в военных частях и подразделениях могут существенно ослабить их боеспособность. В истории проведения военных действий зафиксированы случаи так называемых психиатрических потерь, а их процент иногда даже превышал отметку в $50 \%$ [4, с. 200-232; 10 , p. 190-208]. В течение Первой мировой войны в сербской армии, находившейся в очень трудных условиях, болезненный личный состав которой противостоял многочисленному противнику, но в которой была очень высокая моральная подготовка, - зафиксировано всего два случая психотравмированных бойцов. Необходимо иметь в виду, что в этой войне погибло более четверти всех взрослых жителей Сербии.

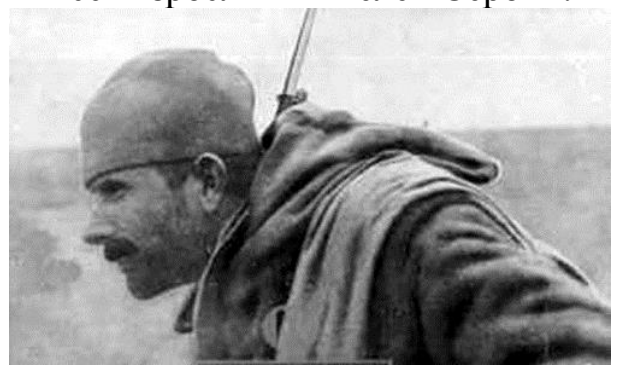

Рис.1. Сербский солдат в Первой мировой войне.

В этой войне (1914-1918) зарегистрировано всего

несколько психиатрических расстройств.

Fig. 1. Serbian Soldier in the First World War (1914-1918). In the Serbian Army there were only few psychiatric disorders

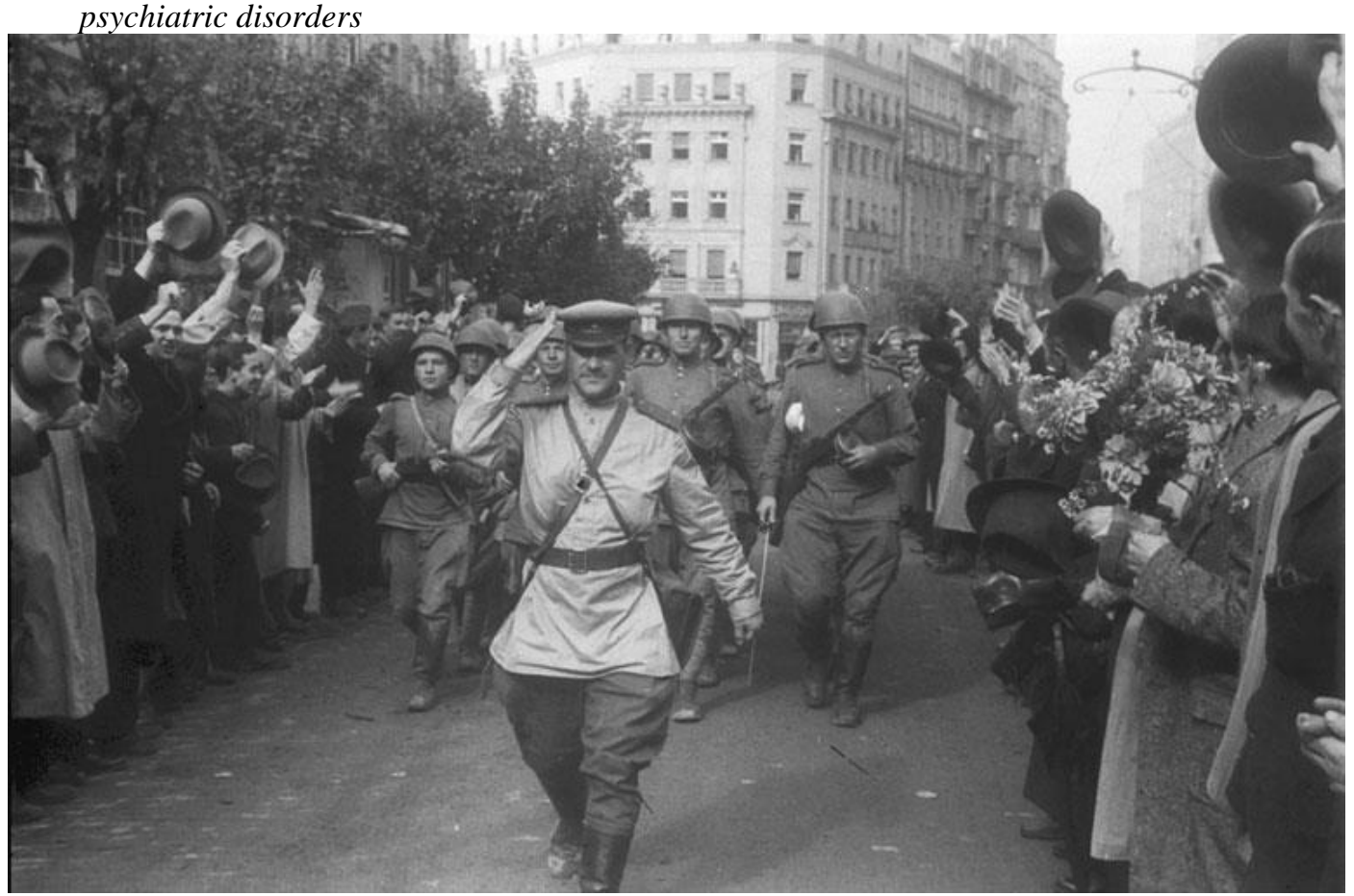

Рис. 2. Процент психиатрических больных в специиализированных госпиталях армейского и фронтового района составлял $6 \%$, что говорит о высокой моральной подготовке советской армии (Белград, 1945).

Fig. 2. Percent of psychiatric disorders in the Russian Red Army in the Second World War was $6 \%$. That fact gives evidence for high morale of Russian soldiers (Russian Army in Belgrade, 1945) 
Представление данных о психиатрических потерях в некоторых армиях

Таблииа (согласно П. Костич [4]) / Table. Mental disorders in diferent armies [4]

\begin{tabular}{|c|c|c|c|c|}
\hline Война / War & Армия / Army & $\begin{array}{l}\text { Психиатрические } \\
\text { потери / Mental } \\
\text { disorders }\end{array}$ & Нарушения / Infringements & Комментарий / Comment \\
\hline I мировая война & $\begin{array}{c}\text { Великобритания } \\
\text { (Англия) }\end{array}$ & $7,4 \%$ & Mackensie - Soldier Heart & $\begin{array}{c}346 \text { солдат были } \\
\text { расстреляны из-за плохой } \\
\text { морали }\end{array}$ \\
\hline I мировая война & Сербия & $0 \%$ & 0 & \\
\hline II мировая война & США & $14 \%$ & $\begin{array}{c}\text { На } 1 \text { отравленного приходилось } \\
20 \text { невротиков со схожими } \\
\text { симптомами }\end{array}$ & $\begin{array}{c}50 \text { \% возвращены в строй, } \\
\text { a } 41 \text { \% в тыл }\end{array}$ \\
\hline II мировая война & Германия & Нет данных & & $\begin{array}{c}\text { Все солдаты с } \\
\text { психическими } \\
\text { нарушениями } \\
\text { расстреляны или } \\
\text { повешены и объявлены } \\
\text { трусами }\end{array}$ \\
\hline II мировая война & Красная Армия & $\begin{array}{c}\text { 6-11\% } \\
\text { (Н.М. Тимофеев) }\end{array}$ & $\begin{array}{c}\text { истерия, неврастения, } \\
\text { реактивный невроз }\end{array}$ & $\begin{array}{c}88,2 \text { \% возвращено в } \\
\text { строй }\end{array}$ \\
\hline II мировая война & Югославская армия & $\begin{array}{l}\text { 0,6 \% до } 1943 \text { г. } \\
52 \% \text { до } 1945 \text { г. }\end{array}$ & $\begin{array}{c}\text { истерическая реакция, } \\
\text { эпилепсия }\end{array}$ & $\begin{array}{c}\text { Повышение показателя с } \\
\text { введением военной } \\
\text { обязанности }\end{array}$ \\
\hline
\end{tabular}

Интересен тот факт, что количество психотравмированных лиц в тылу было намного больше, чем на передовой, а самое меньшее количество таких лиц было в специализированных подразделениях. Больше психотравмированных было в атаках, чем в обороне. В начале и в конце войны и даже в мирное время существенно больше фиксируется психотравмированных лиц, чем во время самых ужасных военных действий.

Из опыта военных психологов в период бомбардировок НАТО Республики Югославии заметим, что довольно большое число резервистов из Пиротского района было направлено на психиатрические осмотры перед бомбардировками пригородных участков, гораздо больше, чем это было в начале бомбардировок и когда они стали интенсивными. В мирное время в течение службы в армии были замечены более частые случаи «самоволки» или нанесения самоповреждений в подразделениях по сравнению с периодом ведения военных операций $[5 ; 8 ; 7$, с. 77].

Прежде чем продолжать рассматривать настоящее явление, необходимо определить и разграничить такие понятия как стресс, травма и посттравматическое стрессовое расстройство (ПТСР).

Стресс представляет собой «тревожное событие жизни, которое сопровождают биохимические, физиологические и когнитивные изменения и изменения в поведении с целью долгосрочного приспособления и адаптации человека к ситуации, в которой находятся под угрозой его жизненные ценности...» [4, с. 201].

В отличие от стресса травма определяется как «внезапное и жестокое событие, которое затрагивает личность настолько сильно, что она временно теряет психологическое равновесие и ведет себя неподобающим образом и/или у нее проявляются симптомы физического (телесного) либо душевного расстройства» [4, с. 202]. В этом смысле война представляет собой общественный стресс, который наступает, когда в высшей степени находится под угрозой выживание индивидуальной личности и целых социальных групп, к которым она принадлежит.

В соответствии с критериями диагностики ДСМ-4 (Самарджич, Шпирич) посттравматическое стрессовое расстройство (ПТСР) обладает следующими характеристиками [9, с. 49].

А) Человек подвергался травматическому событию и при этом 1) пережил, присутствовал или столкнулся с одним или несколькими событиями, которые подразумевали фактическую или надвигающуюся смерть либо тяжелые физические повреждения или угрозу физической неприкосновенности его личности либо другого человека и 2) реакция этого человека подразумевает интенсивный страх, беспомощность и ужас.

Б) Симптомы повторного переживания травмы приводят к одному из следующих пяти симптомов:

1) рекуррентные (повторные), навязчивые и неприятные воспоминания о травматическом событии; 
2) рекуррентные неприятные сны о травматическом событии;

3) впечатление о том, что травма снова происходит через а) сопереживание травмы; б) галлюцинации; в) диссоциативные эпизоды возвращения в травматическое событие при внезапном пробуждении;

4) очень выраженный дискомфорт при контакте с раздражителями, которые символизируют какой-либо аспект травмы либо напоминают о ней и

5) физиологическая реакция.

В) Симптомы забывания ситуаций, связанных с травмой или «обобщенное онемение» с проявлением не менее трех симптомов из следующих: 1) избежание размышлений, переживаний, чувств либо разговоров, которые касаются травмы; 2) избежание осуществления деятельности, мест или людей в связи с травмой; 3) невозможность вспомнить аспекты травмы; 4) снижение интереса к участию в деятельности; 5) чувство дистанции или отчуждения к другим людям; 6) сужение сферы чувствительности и 7) чувство бесперспективности по отношению а) планов работы, б) планов брака и семьи, в) ожиданий и планов старости и будущего.

Г) Симптомы раздражительности (два из пяти): 1) затруднительное засыпание или непостоянная фаза сна; 2) раздражительность или вспышки гнева; 3) трудности со сосредоточением внимания; 4) сверхнастороженность и 5) выраженная реакция испуга и подергивания и нервные тики на безобидные раздражители.

Д) Продолжительность данных изменений наблюдается дольше месяца и приводит к нарушениям в социальном, профессиональном и в других планах во всех важных областях жизедеятельности.

Как мы уже упомянули, война представляет собой общественный стресс, который возникает в случае крайней угрозы выживанию индивидуальной личности либо целых общественных групп, к которым она относится. Это касается и представителей военных подразделений (солдат и офицеров), и мирного охваченного ужасами войны населения.

Посттравматическое стрессовое расстройство у солдат может проявиться разными способами (всего четыре): а) в самом бою, без предыдущего травматического опыта; б) в бою после пережитого травматического события; в) после проведения боя, в перерыве между боевыми действиями или после ухода с передовой линии и г) после войны, окончания боевых действий и после демобилизации в мирное время.
Во избежание психиатрических потерь среди солдат необходимо принять меры для приобретения сопротивляемости к возникновению страха, тревоги, паники и психических расстройств [2, c. 106-111]. Некоторые из таких мер следующие:

1) Развитие личной и коллективной мотивированности к победе.

2) Реалистическая, своевременная

и интенсивная боевая подготовка.

3) Развитие реалистического понимания опасности и ужасов войны.

4) Хорошая и своевременная информированность о глобальной и военной ситуации.

5) Личный пример офицеров для подражания, равнение на храбрых личностей.

6) Постоянное поддерживание контактов с реальностью и организация деятельности.

7) Постепенный переход боевого состава от выполнения более легких к тяжелым боевым задачам.

8) Разъяснение, что страх - это нормальное явление.

9) Ознакомление личности с собственной психической жизнью.

10) Развитие солидарности коллектива и подразделения.

11) Навыки и мудрость управления и командования.

Что касается устранения боевой усталости, необходимо применять основные четыре принципа:

1) Быстрота. Необходимо как можно скорее реагировать, если это возможно, и на самой «боевой линии». На начальной стадии травматизированное лицо доступно, восприимчиво к влиянию коллектива и может легче пройти через кризис. Этот принцип предотвращает попытку (часто неосознанную) достижения вторичной выгоды.

2) Позиция ожидания положительного исхода. Для солдата лучше всего, чтобы он лечился в среде и окружении, в которых он будет считать, что все заинтересованы в его выздоровлении. Следует избегать атмосферы больницы и предотвращать ятрогенизацию ${ }^{1}$ и реализацию вторичной выгоды.

3) Простота. Солдату нужно говорить, что его болезнь не имеет серьезного характера и что она должна лечиться простыми методами.
4) Централизащчия
подразумевает организованную госпитализацию через один

\footnotetext{
${ }^{1}$ Ятрогения - ухудшение психического (в данном контексте) состояния пациента из-за неправильного истолкования им слов и действий врачей. (Прим. ред.)
} 
центр, который располагается как можно ближе к месту военных действий. Таким образом обеспечивается, чтобы профессиональная служба своевременно приняла более тяжелые случаи и чтобы не создавалась возможность моделирования и обострения психотравмы в целях достижения вторичной выгоды.

В процессе проведения военных действий в регионе бывшей Югославии, а также в период бомбардировок НАТО в 1999 году военные психологи в своих боевых подразделениях непосредственно работали с солдатами и офицерами с целью профилактики психических расстройств на войне.

Что касается лечения психически травмированных лиц, на фронте оно осуществлялось по поэтапному принципу. Военные врачи и психологи в подразделениях, которые не были охвачены войной, направляли своих солдат в психиатрические службы Военного госпиталя в Нише и в Военномедицинскую академию в Белград. В Нишском регионе осуществлялось сотрудничество с психологом из Военного госпиталя Божидаром Любишичем [6], а также с высшим должностным командованием.

Интересно, что когда речь идет о ПТСР, главные расстройства проявлялись уже после окончания боевых действий, даже по прошествии нескольких лет после войны; в мирное время они в первую очередь выражались нарушениями в социальной, семейной, профессиональной деятельности и в прочих важных сферах жизнедеятельности. Об этом свидетельствуют многочисленные истории болезни и заключения бригадного психолога. В дальнейшем тексте мы приведем всего лишь несколько типичных примеров ПТСР у солдат и офицеров из подразделений Пиротского и Нишского гарнизонов.

Пример 1: капитан, 40 лет, женат, отец шестилетней дочери, с 20-летним стажем военной службы. Провел шесть месяцев на войне. Храбро и самоотвержено сражался. После возвращения наблюдаются проблемы со сном, его мучают кошмары и сны с картинами военных действий (чаще всего ему снятся три его погибших солдата). Чувствует усталость, бессилие, жалуется на головные боли в лобной области. Отчужден, с бурными вспышками гнева и агрессивным поведением. В недавней сcоре с женой сломал стол. Сам пугается своих неконтролируемых реакций, поэтому избегает контактов с ребенком и женой. На тесте умственных способностей показал высокие результаты, а тесты личности (ПИЕ, ММПИ-201) говорят о невротическом реагировании и о симптомах ПТСР. Направлен в отделение невропсихиатрии Военного госпиталя в Нише и после терапии лекарствами симптомы у него стали чуть слабее, но позже появились подергивания и нервные тики на малейшие раздражители. Через десять лет переживает тяжелую семейную трагедию. После этого выявлены серьезные депрессивные отклонения, из-за чего несколько раз был госпитализирован.

Пример 2: солдат, 22 года, явился на прием к психологу из-за страхов, бессоницы, ночных кошмаров, тремора, потери аппетита и общего перевозбуждения. Появление своих проблем он связывает с травматическим событием, произошедшим два года назад, когда он присутствовал при ранении лучшего друга, которого ножом уколол один албанец. На службе в армии чувствует страх и стыдится, что не будет в состоянии выполнить обязательства, которых от него ожидают командиры. Родителям по телефону повторяет суицидальные мысли и намерения: «я убью себя». Интеллектуальные способности на уровне выше среднего, но в подразделении неэффективен. Личностные тесты говорят о том, что речь идет о гиперчувствительной личности с крайне низким порогом фрустрационной толерантности, упадком жизненного динамизма, что влияет на слабую мотивированность. Ночью иногда появляется сомнамбулизм, резко прыгает с кровати, бьет руками по тумбочкам в спальной комнате и кричит: «Вперед, бежим...». После нескольких психиатрических процедур и контактов с военным психологом его мотивированность улучшена, жизненный тонус поднялся и стабилизировался, а при поддержке боевых товарищей успешно закончил военную службу.

Пример 3: капитан, женат, имеет двух сыновей, семнадцати и пяти лет. Как командир роты неоднократно получал благодарности, имеет шесть медалей и два денежных приза от командования. Участвовал в боевых действиях в Хорватии и Косово. Чудом выжил при обстреле казармы, когда смело вытащил коллегу из-под завалов и вынес его на плечах. Получил удары в голову (спереди справа и в области шеи), после чего потерял сознание. Он отказался от осмотра, но в последующие дни у него возникают головные боли в височной области («как будто кто-то тыкает отверткой») и слабость в ногах и теле. При утреннем пробуждении чувствует сильное головокружение и потерю равновесия. Часто не может сосредоточиться, внезапно возникает разрыв и блокировка мысли в процессе работы. Он снова после трех месяцев был задействован в боевых операциях, но из-за психологических проблем отправлен в Военный госпиталь, где его госпитализировали. Жалуется на 
больничную обстановку, отказывается от лечения, хочет вернуться на фронт. Со злостью, агрессивно реагирует на врачей и весь персонал больницы. После этого чувствует угрызения совести из-за такого своего поведения. Ночью часто просыпается внезапно с чувством страха и сильной тахикардии. Его мучают кошмары и навязчивые повторения травматических картин с поля боя. Внезапная потеря веса (около 15 кг), а в поведении преобладает подавленное настроение с падением динамизма - аппетита, либидо и сна. Личностные тесты показывают замкнутость, склонность к отчуждению, снижение социальных интересов с предпочтением психосоматических реакций и конверсивным реагированием. Отмечается чувство собственной неполноценности, отсутствие перспектив, потеря воли и пессимизм. Со временем происходит улучшение адаптации к условиям мирного времени, но психосоматические расстройства остаются в виде артериальной гипертензии и тахикардии с чувствами отчуждения и изменения.

В приведенных выше примерах солдат и офицеров непосредственно видны симптомы ПТСР. В большинстве случаев речь идет о категориях появления дискомфорта после войны и окончания боевых действий в мирное время, когда возникают серьезные нарушения в социальном, профессиональном плане и в других важных областях жизнедеятельности. Наблюдая за отдельными примерами на протяжении определенного времени, мы увидели, что острые психические отклонения проявляются незначительно, но что очень часты психосоматические нарушения в виде артериальной гипертензии, сердечных болезней, астматических симптомов, проблем с пищеварением, язвы и прочего. Из-за нарушенного состояния здоровья многие из таких больных вышли на пенсию, а некоторые и умерли от инфаркта, инсульта, суицида и пр.

Результаты представленного анализа свидетельствуют о том, что необходимо применять профилактические меры до проведения боевых действий, во время военных действий, но также необходимо длительно наблюдать за психическим и медицинским состоянием участников военных операций и после их окончания.

\section{Литература}

1. Желтов, А.С. Солдат и война. М.: Изд-во Министерства обороны СССР, 1971.318 с.

2. Капор, Г. Ратна психијатрија. Београд: Војноиздавачки завод, 1982. $444 \mathrm{c}$.

3. Клајн, Х. Ратна неуроза Југословена. Београд: Народна армија, $1953.155 \mathrm{c}$.
4. Костић, П. Психологија борбених јединица. Београд: НИЦ Војска, 2000. 327 с.

5. Милићевић, Н. М. Карактеристике личности адолесцената са аутоагресивним тенденцијама // Годишњак за психологију. №. 1 (1). Филозофски факултет Ниш, 2002. С. 225-233.

6. Љубишић, Б.†,

Милићевић, Н.М., Миленовић, М.Б. Процена успешности селекције оператора противоклопних вођених ракета (ПОВР) Војсци Југославије // 46. Научно стручни скуп психолога Србије - Сабор 1998. Књига резимеа. Аранђеловац, 1998. С. 64-65.

7. Милићевић, Н.М. Профил индекс емоција адолесцената војника са ранијим самоповређивањима // 44. Научно стручни скуп психолога Србије - Сабор 1996. Књига резимеа. Зборник радова. Друштво психолога Србије. Врњачка Бања, 1996. С. 77-78.

8. Милићевић, Н.М., Цветковић, В. Анализа узорка и мотива самовољног удаљавања из јединица // Нови Гласник - војностручни интервидовски часопис. Београд: Војноиздавачки завод, 2000. № 2. С. 13-18.

9. Самарџић, Р., Шпирић, Ж. Посттрауматски стресни поремећај // Војносанитетски Преглед. 2004. № 61(1). C. 47-57.

10. Watson, $P$. War on the mind: The military uses and abuses of psychology. New York: Basic Books, 1978. 534 p.

\section{References}

1. Zheltov, A. S. A Soldier and a War. Moscow: Publishing House of the Ministry of Defence of USSR, $1971.318 \mathrm{p}$.

2. Kapor, G. Military Psychiatry. Belgrade: Vojnoizdavacki zavod, $1982.444 \mathrm{p}$.

3. Klajn, H. Yugoslav War Neurosis. Belgrad: Narodna armija, 1953.

4. Kostic, P. Psychology of Combat Units. Belgrad: Vojska NIC, 2000.

5. Milicevic, N. M. Personality Characteristics of Adolescents with Auto Aggressive Tendencies. Godishnjak za psikhologiju [Annual Psychology Journal]. Nis: University of Nis, Faculty of Philosophy. No. 1(1) (2002). Pp. 225-233.

6. Ljubišić, B.†, Milicevic, N. M, Milenović, M. B. The Evaluation of Selection of Anti-Tank Guided Missile Operators in Yugoslav Army. $46^{\text {th }}$ Annual Conference of the Serbian Psychological Association - Sabor 1998. Abstract book. Arandjelovac, 1988. Pp 64-65.

7. Milicevic, N. M. Emotion Profile Index of Adolescent Soldiers with Previous Self-Injury. $44^{\text {th }}$ Annual Conference of the Serbian Psychological Association - Sabor 1996. Abstract book. Vrnjacka Banja, 1996. Pp. 77-78.

8. Milicevic, N. M. \& Cvetkovich, V. Analysis of Causes and Motivations of Soldiers Arbitarily Leaving their Units. Novi Glasnik [New Courier - Military professional periodical of the Army of Serbia and Monte Negro]. Belgrade: Vojnoizdavacki zavod. No. 2 (2000). Pp. 13-18.

9. Samardžic, R. and Spiric, Z. M. Posttraumatic Stress Disorder. Vojnosanitetski Pregled [Military medical review]. No. 61(1) (2004). Pp. 47-57.

10. Watson, P. War on the Mind: The Military Uses and Abuses of Psychology. New York: Basic Books, 1978. 534 p. 